\title{
SALVajes, bárbaros y brutos. De la Grecia clásica al MÉXICO CONTEMPORÁNEO
}

\author{
Oscar Muñoz Morán
}

Resumen: La idea del Otro ligada a la del salvaje ha sido desde la Antigüedad una obsesión de las diferentes culturas. Su definición ha abarcado desde las descripciones fantásticas de monstruos y seres infrahumanos, hasta la de territorios en los que se ubicaban. Desiertos, selvas, altas montañas o, simplemente, las últimas tierras conocidas durante la Edad Media, eran los lugares del extraño. Con el ejemplo de Latinoamérica en general y México en particular, la relación existente entre esos seres llamados "salvajes", "bárbaros" o "brutos" y el espacio que habitaban, reconocido como lejano a la propia concepción cultural, será el eje central de estas páginas.

Palabras clave: Salvaje, bárbaro, territorio, pasado, cultura, purépechas, México.

Enviado a dictamen: 18 de agosto del 2008. Aprobación: 29 de octubre de 2008.

Dr.Oscar Muñoz Morán, doctor en Antropología Social, Universidad de Salamanca, España, Investigador de la Red de Museos Etnográficos de Asturias-Museo del Pueblo de Asturias, Calle Gil Blas, 26, 1ํㅡ, 33008, Oviedo, España, (0034) 985210184/0034 652813659, correo electrónico: oscarmmoran@hotmail.com.
Abstract: "El Otro" and the wildness, since ancient times has been an obsession of different cultures. Its definition has ranged from descriptions of fantastic monsters and subhuman beings, to territories where they have been located. Deserts, rain forests, high mountains, or simply, the latest land known during the Middle Ages, were places of strange. With the example of Latin America and Mexico, the relationship between these "wild", "barbaric" or "brutos" and living space, recognized as far from one's own cultural conception, will be the centrepiece of these pages.

Key words: Savage, Barbarian, territory, past, culture, purépechas, Mexico.

T a idea del Otro ligada a la del salvaje ha sido desde la Antigüedad una obsesión de las diferentes culturas. Su definición ha abarcado desde las descripciones fantásticas de monstruos y seres infrahumanos, hasta la de territorios en los que se ubicaban. Desiertos, selvas, altas montañas o, simplemente, las últimas tierras conocidas durante la Edad Media, eran los lugares del extraño. Con el ejemplo de Latinoamérica en general y México en particular, la relación existente entre esos seres llamados "salvajes", "bárbaros" o "brutos" y el espacio que habitaban, reconocido como lejano a la propia concepción cultural, será el eje central de 
estas páginas. El ejemplo etnográfico de la comunidad purépecha de Sevina nos ayudará a entender mejor cómo la distancia temporal y espacial resulta esencial para caracterizar al Otro.

\section{El "salvaje" y/o el "bárbaro" entre griegos, roma- nos y hombres del Medievo}

En las escrituras de los griegos de la antigüedad, como cultura pionera en el registro de su entorno, encontramos las primeras definiciones del Otro, es decir, de todos aquellos seres que no pertenecían a su mundo conocido. Llamado en unas ocasiones "salvaje" y en otras "bárbaro", ambos vocablos no eran sinónimos, ya que el primero (como parte del mito) antecede al segundo (la realidad).

Woortmann ha señalado cómo las características usadas para definir al salvaje estaban determinadas por la necesidad de buscar una definición a lo que ellos mismos, los griegos, eran. Ante la inexistencia de un término adecuado para lo que hoy en día conocemos como "civilización", 'tuvieron que adecuar la definición a lo que les caracterizaba respecto al resto de las culturas conocidas. Ellos eran, ante todo, aquellos que habitaban el mundo desarrollado y ordenado - hemeros (domesticado) - en la polis o ciudad: "Combinadas, transmitían la idea de orden, una ciudad gobernada por leyes justas; fuera de ella, sólo podría existir el desorden" (Woortmann, 1997: 6). ${ }^{2}$

Los primeros que no pertenecían a este mundo regido por las leyes griegas son los seres mitológicos: centauros, cíclopes, ${ }^{3}$ ninfas. Todos ellos descritos como seres monstruosos y alejados del mundo conocido. Estas fronteras míticas se abrieron a la realidad tras la obra de Heródoto (Historiae, del 444 a.C.). El llamado "primer historiador" o "primer etnógrafo", expuso la existencia de una serie de culturas lejanas en el espacio y en las costumbres, los pueblos a los que se enfrentaron en sus guerras, que vinieron a reafirmar ese concepto del salvaje como ser alejado y extraño. De todas formas, Hurbon (1993) ha señalado que los griegos nunca usaron la palabra "bárbaro" para referirse a los persas, que eran esos grupos a los que se enfrentaron. Se usaron vocablos como xeinoi (extranjero) o allothroi (gente de otra lengua), pero nunca bárbaro (Hurbon, 1993: 29). Aparte de las discusiones sobre si los nuevos salvajes eran humanos (Heródoto) o simplemente animales (Aristóteles) a los que no habría que tener en consideración, aparece por primera vez la diferenciación del otro, de una forma peyorativa, y el uso de determinados términos para referirse a él. Ese bárbaro, en líneas generales, parecía estar un estadio por encima del salvaje, más cercano al hombre. El salvaje, mientras tanto, era un ser casi animal (Woortmann, 1997: 9). Aunque la distinción entre un término u otro no parece estar nunca muy clara en el mundo griego, sí es importante señalar que los grupos humanos que ahora se les enfrentan (los persas), comienzan a ser tratados - pero no denominados, como hemos visto- como bárbaros. Es decir, aparecen en el mundo heleno una serie de grupos de seres (humanos, animales o un estadio intermedio) que se anteponen a su civilización.

Los salvajes y/o bárbaros pasaron a ser esos seres medio animales, que iban desnudos, carecían de lenguaje (al menos comprensible), practicaban el canibalismo y vivían en lugares lejanos como desiertos o altas montañas (Barabas, 2000: 10). Es decir, era aquel que no vivía en la polis, sino en el agros, lo cual significaba que tenía un contacto directo y cercano con la naturaleza. Esto lo podía convertir, al mismo tiempo, en un ser noble o, cuanto menos, representante de un vida incorrupta ya que parecía vivir en plena armonía con el entorno.

Platón, más de un siglo después, en su obra Leyes, nos dio las claves para entender cómo el concepto de bárbaro estaba condicionado por los territorios que habitaba. Según Caro Baroja, el autor clásico establecía tres estadios de desarrollo humano, tres politeias:

Una en lo alto de los montes: la más simple y silvestre. Otra, después, en la falda de los mismos montes, que, poco a poco, fue adquiriendo confianza y ánimo. La tercera, al final, en las llanuras (Caro Baroja, 1959: 384). ${ }^{4}$ 
Estaúltima sería aquella donde residían ellos, en las polis, el hombre civilizado y plenamente desarrollado, dondelas leyes ordenaban el comportamiento social. Esta sociedad era la del progreso y el desarrollo humano, pero también, la de la corrupción del estado natural de las cosas.

En el extremo contrario estaba, por tanto, ese bárbaro y/o salvaje que era considerado el estado primigenio del hombre, el '“sistema ciclópeo', es decir, en un estado de inocencia primitiva" (Caro Baroja, 1959: 384). Estos seres son ubicados por Platón en un punto del plano espacio-tiempo bien determinado, de tal forma que parecerían una especie de representación del mundo mítico (de nuevo vemos como se relaciona el mito - salvaje-con la realidad-bárbaro-) y, como tal, situado en la antigüedad pero, sobre todo, en un entorno distante. Su hábitat serían aquellos lugares inhóspitos, lejanos y extraños (Caro Baroja, 1959: 385), en muchos casos no conocidos. Platón los ubica en su teoría en las altas montañas, pero también se hace en desiertos o bosques de países distantes.

Se establece, por tanto, la dicotomía que divide el territorio entre espacio habitado y ordenado. La polis por un lado, y el entorno salvaje por otro, donde seres primitivos y casi animales, habitan y hacen uso de costumbres extrañas y regidas por la única ley que establece la propia naturaleza. El salvaje es el extraño, el que vive fuera de las leyes conocidas.

Así sucedió con los romanos, varios siglos después, cuando tuvieron que enfrentarse a los pueblos del centro de Europa. Tras la conquista e invasión de estas tierras, fueron muchas las voces que se encargaron de difundir los atributos negativos de los habitantes originarios de las mismas. La acción contra los casi-animales que habitaban esos bosques estaba plenamente validada, ya que ellos eran los baluartes de la civilización.

Schama (1995: 83-84) nos muestra cómo, antes de que los ejércitos romanos llegaran a esos profundos bosques de tierras desconocidas, frías y oscuras; había sido Tácito quien, en su obra Germania, había presentado la imagen de unos bosques donde habitaban "criaturas" inhumanas y monstruosas, capaces, incluso, de hacer sacrificios humanos. Pese a estas características ampliamente negativas atribuidas por el autor, el mismo Tácito llegó hablar de los germanos, como de un ejemplo de nobleza y simplicidad, virtudes perdidas en la sociedad romana.

Gran parte de esta imagen, sin duda alguna heredera de sus predecesores, los griegos, está determinada por el territorio. Es decir, un bosque salvaje, peligroso y fuera del orden conocido, daba las mismas características a quienes lo habitaban. Los romanos, aquellos que estaban en las urbes, no entendían un ordenamiento de la sociedad fuera de éstas. El mismo término de "bosque" en inglés, forest, posiblemente sea una derivación del latín foris, es decir, "fuera de". Aunque, como dice Schama (1995: 144), no hace referencia exactamente a una concepción espacial, es decir, fuera de un lugar, "sino más bien de administración, regulada por las leyes romanas y la ley común”. Ya decía Tácito, que ninguno de los pueblos bárbaros habitaba en ciudades, sino en asentamientos individuales, separados y regidos tan sólo por la orografía del terreno. Y, además, en mitad del espeso y peligroso bosque donde convivían con seres extraordinarios, bestias y monstruos (Schama, 1995: 84).

Ya en la Edad Media, el salvaje pierde la poca condición de nobleza que pudiera tener en la antigüedad. Siguiendo las teorías de algunos clásicos, especialmente de Aristóteles, en el medievo ${ }^{5}$ se considera al bárbaro una semi-bestia, muy alejada de lo civilizado. Además, se añade la necesidad de que el infiel fuera redimido, convertido en un hombre de fe. Bajo un pensamiento claramente escatológico y teológico, se comienza a dividir el mundo entre lo que está dentro del cristianismo, y lo que queda al margen de la palabra de Dios:

Se trata, fundamentalmente, de una separación, en el tiempo, entre paganos y cristianos, ${ }^{6}$ así como en el espacio entre fieles e infieles; cristianos y paganos; civilizados y bárbaros/salvajes (Woortmann, 1997: 18). 
La Cristiandad era el espacio a partir del cual, todo lo que estaba dentro pertenecía a la categoría de la civilización y lo que quedaba fuera eran considerados como "paganos bárbaros" (Woortmann, 1997: 26). Dios se había encargado de crear un mundo perfecto donde estos salvajes jugaban el papel de las bestias que vivían en desorden. Fuera de la verdad cristiana, todo era barbarie.

A lo largo de la Edad Media, el pensamiento evolucionó desde un comienzo en que la distinción entre el salvaje y el bárbaro no estaba tan clara, hasta el Renacimiento donde se empezó a manejar el concepto del "buen salvaje". Al principio, el salvaje era ese ser desconocido, mítico e imaginario (herencia clásica) que no conocía la palabra de Dios y que, normalmente, vivía en territorios alejados e inhóspitos. El bárbaro, por su parte, era un pueblo cercano, violento y resistente a la fe. Era aquel al que se quería conquistar o imponer la religión (Woortmann, 1997: 41). La línea entre uno y otro era tan pequeña, que podía ser superada en cualquier momento.

El elemento territorial continuaba siendo, en el imaginario medieval, sumamente importante. El salvaje y la tierra accidentada y peligrosa, desconocida y profunda, seguían estando relacionados. Los bosques, como ya vimos con Tácito durante la época romana, eran lugares impredecibles, donde las leyes no tenían validez y donde habitaban infinidad de seres fantásticos. Durante la Edad Media muchos de esos bosques del centro de Europa, pasaron a formar parte de un espacio intermedio entre el mundo cristiano y el pagano. Eran como islas en mitad de la Cristiandad, vistas por muchos monjes o ermitaños, como lugares donde poner a prueba su fe y su fuerza religiosa (Schama, 1995: 227) ${ }^{7}$

Con la llegada del Renacimiento, aunque la visión inmovilista del mundo cristiano continuó, se apuntarán algunos cambios como la mayor presencia del hombre en la concepción del mundo, en perjuicio de la centralidad de Dios. La imagen del "buen salvaje" gana cierto terreno sobre la del salvaje animal, siendo, no obstante, ésta la que sigue prevaleciendo en la mayor parte de los círculos intelectuales del momento (Barabas, 2000: 11).

Ciertos parámetros se cuestionan tras el descubrimiento de América. Se abren debates interesantes sobre la condición del salvaje americano — como el que existió entre Bartolomé de Las Casas y Juan Ginés de Sepúlveda - pero, en líneas generales, se aplica la doctrina heredera del mundo clásico y de los siglos medievales. En Europa, por ejemplo, los irlandeses — que hasta entonces eran considerados los más bárbaros entre los bárbaros europeos por vivir en el fin del mundo- dejan de ser salvajes, pues es evidente que sus tierras ya no son las últimas conocidas. Ahora están dentro de la Cristiandad. Cercanos y comprensibles, pueden ser redimidos con la palabra de Dios. Porque

\section{El salvaje siempre estuvo asociado a un lugar no co- nocido, expresado en los mapas por ilustraciones de monstruos, o expresiones como 'tierra de gigantes', atribuida al extremo meridional de América del Sur. El salvaje existía en regiones salvajes, es decir, regiones no domesticadas (Woortmann, 1997: 50).}

América es ahora el conjunto de tierras y regiones donde, tanto ellas como sus habitantes, representan a la perfección aquello que se entiende como salvaje. Que, por otra parte, es ahora aquel que puede ser salvado con la evangelización y purificación de su alma (al margen de disputas teológicas sobre si tenían alma o no).

\section{El salvaje en América. Algunos ejemplos etno- gráficos}

Cuando españoles y portugueses llegaron a América en el siglo XV, se encontraron, por tanto, con unas tierras y habitantes que parecían confirmar todo aquello que desde la Grecia clásica se había dicho del hombre salvaje y de los lugares silvestres. ${ }^{8}$ Los eclesiásticos llegados al Nuevo Mundo quisieron sacar del atraso evolutivo (teológico) a los inocentes - uno de los calificativos que con mayor frecuencia se les aplicaba-indios, y conver- 
tirles mediante la evangelización. Pero un sector de esos frailes y monjes se opuso a la concepción que sobre los indios se aplicó, produciéndose serias disputas sobre si aplicarles el término de "buen salvaje" o, simplemente, esclavizarlos por su condición de no humanos.

Ya fuera desde un lado u otro, se partía siempre de una idea clara: el indio no era cristiano y, como tal, no era civilizado. Por tanto, era salvaje. Tres atributos del mismo fueron destacados por encima del resto: la desnudez, clara representación de la animalidad del indio; el canibalismo, que le acercaba peligrosamente a las bestias míticas; y su hábitat salvaje (Barabas, 2000: 12). Lugares que van desde remotas islas, pasando por altas e inaccesibles cumbres, selvas profundas e, incluso, desiertos e infinitas llanuras, eran las localizaciones, no únicamente de grupos de indios salvajes y bárbaros, sino también de bestias, monstruos y seres sobrenaturales con los que parecían convivir.

Desde entonces hasta la actualidad, no sólo han cambiado las relaciones de poder o las posiciones del indígena en sus territorios, sino que se han recibido nuevas colonizaciones y aplicado nuevas nociones que sobre el salvaje se han tenido y se tienen.

En Latinoamérica, la selva, y en especial la Amazonía, fue el hábitat principal de donde se alimentó la imagen del salvaje. El interior de ella, todavía hoy habitada por grupos indígenas que, o bien nunca han tenido contacto con la sociedad moderna (los menos), o bien —el caso más común - están en una situación de "contacto inicial", 9 es la representación fiel del territorio inhóspito, desconocido y cuyo control ha estado fuera del alcance de la modernidad hasta, probablemente, la actualidad.

Aquellos que habitaban, y habitan, sus profundidades han estado siempre fuera de la comprensión del europeo antes, o del mestizo ahora (e incluso, como veremos, de determinados grupos indígenas). Chavarría (1999) nos ha mostrado cómo en el Departamento de Madre de Dios, Perú, se ha creado el término huarayo para referirse a aquellos que son considerados indígenas bárbaros, que viven y se comportan casi como animales. Usado como sinónimo de "salvaje" o "ignorante", "servía para expresar el desprecio que la gente de habla castellana sentía por cualquier indígena", o para referirse "a cualquier personas con rasgos indígenas (no andinos)". Lo más interesante es que el término huarayo ha sido hoy adoptado en la zona para aludir a todo aquel que parece "raro" o diferente, de hecho, algunos artículos con representaciones de indios norteamericanos, son vendidos a los turistas junto a la palabra "huarayo" (Chavarría, 1999: 18).

Es importante apuntar que, inicialmente, se usó para referirse a los Ese Eja ("gente verdadera"), y que después derivó en lo que se conoce hoy en día. Incluso en Paraguay existe una etnia conocida también como Huarayos, ya que los primeros occidentales que entraron en contacto con unos y otros, aunque posiblemente capaces de diferenciarlos, aplicaron el mismo término despectivo para todos. Todos eran salvajes.

Más complicados de determinar parecen los límites del vocablo bugre, en la Amazonía brasileña. Nos dice Greg Urban (1996) que "el término significa 'indio' o 'salvaje'. Connota brutalidad, falsedad e imperfección". Afirma que el propio término "indio" resultaba insuficiente para hacer referencia a un tipo especial de grupo, más violento, hostil y feroz. Fueron los nuevos conquistadores (empresas y compañías) alemanas, quienes ayudaron a la construcción de esta imagen de los bugre cuando se la aplicaron a los indígenas de la selva. Estos, desde 1914 aproximadamente, se autodenominaron botocudo, término portugués que, hoy en día, es una especie de sinónimo de bugre. Es interesante cómo, al igual que en Madre de Dios, la palabra ha pervivido en el tiempo y se sigue aplicando en la actualidad, no como referencia a un grupo o etnia determinada, sino como un concepto global de identificación con lo bárbaro y lo diferente, que, por otra parte, para el mestizo, suele ser el indígena amazónico (Urban, 1996: 32).

Más al norte de esta zona, en el Putumayo colombiano, Taussig (1991) registró en los años setenta y ochenta 
del siglo pasado, gran parte del imaginario que se había creado del indígena local. El autor muestra cómo tanto durante la conquista española, como durante la industrial del siglo XIX pero, principalmente, el XX; los colonizadores consiguieron construir una imagen de la población autóctona que, una vez asumida e interiorizada por ambas partes, se convirtió en la excusa perfecta para la evangelización, esclavización, explotación o, directamente, eliminación del indio salvaje.

En primer lugar, está el término chuncho, usado ya por los Incas para referirse a todas las tribus de la selva que les hacían frente y que, hoy en día, es incluso usado en algunos festivales como "representación de lo indio, per se" (Taussig, 1991: 230). Su correspondencia en gran parte de la región del Putumayo es el término auca, aplicado inicialmente a todos aquellos indígenas que representaban una especie de estado primigenio, salvaje y, principalmente, alejado de la civilización. Es decir, eran la imagen humanizada de lo inhóspito de la selva (Taussig, 1991: 230, 236).

Desde la creación del estado independiente y la conformación del estado liberal en el siglo XIX, las élites criollas de Colombia tuvieron un especial interés por atribuir al indígena del interior, especialmente aquel más beligerante como los Paez del Putumayo, una imagen alejada del recién creado ciudadano nacional, inserto en un nuevo mundo de progreso e industrialización.

Las fronteras de la cultura de mercado (concebidas idealmente) también separaban la civilización de la barbarie. En el mejor de los casos, indios y africanos poblaban las márgenes de la civilización porque parecían carecer de todo aquello que los liberales criollos identificaban con ella: dinero, comercio, comodidad, higiene, el cristianismo y los valores culturales asociados con estas cosas (Larson, 2002: 52).

Con la aparición del boom tanto de la quinina como del caucho, entre los años cincuenta y setenta del siglo XIX, llegaron compañías europeas a Colombia para su explotación que se encontraron con "impresiones desalentadoras de indios exóticos y paisajes hostiles que impedían las expediciones científicas y el progreso económico" (Larson, 2002: 47). Tanto estos nuevos colonizadores, como las élites liberales con las que estaban aliados, se encargaron de aplicar las teorías de Darwin "para naturalizar las desigualdades raciales y de clase, y racionalizar el ejercicio de la violencia y la dominación en las empresas colonialistas y capitalistas" (Larson, 2002: 49).

Desde entonces, y hasta incluso la segunda oleada del caucho en los años veinte del siglo pasado, las compañías europeas explotaron esas imágenes de salvajismo de la población indígena para poder justificar, principalmente en sus países, las atrocidades que estaban cometiendo contra los autóctonos. Entre estos, eran los chamanes los que mejor representaban las características atribuidas a los indios salvajes, no cristianos, brujos y alejados de la civilización. Los propios chamanes estudiados por Taussig, se han apropiado de esa imagen e intentan aparecer lo más incivilizados posible para, precisamente, resaltar la diferencia con el hombre blanco y sus acciones.

Existía un grupo de población que durante esa década de los años veinte fue especialmente perseguido por una nueva oleada de evangelizadores (Taussig, 1986: 381-389). Considerados como una nueva tribu de salvajes, los Huitotos, eran un estorbo para las compañías recién llegadas desde el Viejo Continente. Eran indígenas salvajes, excluidos, apartados, paganos y peligrosos. Hoy en día, los locales (en este caso los chamanes) hablan de esos huitotos como personas que "no conocen y que conviven con el diablo, sencillamente porque no son Cristianos. Son como perros que no tienen alma" y capaces de ver a fantasmas y espíritus (Taussig, 1986: 378). Estos atributos son con los que los chamanes dejan que, sin problemas, se les identifique.

Hasta el momento, he podido precisar ejemplos de términos contemporáneos aplicados de una forma genérica a todo lo que hace referencia al indígena todavía alejado 
del mundo moderno. Huarayo, bugre o auca, son diferentes términos para un mismo significado: el indio salvaje que todavía vive en la selva y está alejado culturalmente de lo conocido por la sociedad dominante. Con sus diferentes aplicaciones y usos en el tiempo, las poblaciones autóctonas, rara vez, se apropian de estos términos.

Es en los Andes, donde parece que se asume más, por parte de las poblaciones indígenas, esa imagen del salvaje, haciendo de ella una interpretación local. Eso sí, aquí entra en juego un elemento esencial que hasta el momento sólo hemos visto de pasada con los chunchos en el Perú: la relación existente entre salvaje y un tiempo distante, anterior a la llegada de los primeros europeos. Los chunchos son, en el gran festival anual celebrado en las montañas cercanas a Cuzco, la representación del desorden, del caos. Son los hombres de la selva que, en el pasado (en muchos casos, considerados los ancestros), ocupaban el mundo antes de la llegada incluso del Sol y de la luz. Pre-culturizados y salvajes, fueron el caos antes de la llegada del orden (los Incas) (Randall, en Taussig, 1997: 228-230). ${ }^{10}$

Pasando al país vecino, Bolivia, vemos cómo en su altiplano los k'ulta presentan en su "mito" de creación la lucha entre Tatala-Jesucristo y los Supay-Chullpas, siendo estos segundos, conocidos tan solo como Chullpas, una especia de antepasados del grupo, no cristianos ("moros"), "una clase de humanos salvajes y desordenados que pertenecen al pasado" (Abercrombie, 1998: 324). Los Chullpas se caracterizaban por ser no cristianos y por estar muy alejados de la idea de civilización, ya que eran todavía cazadores-recolectores, es decir, no agricultores (Abercrombie, 1998: 325).

Aunque los k'ulta son conscientes de que estos Chullpas eran los habitantes de la región antes de la llegada de la religión católica y de ellos mismos, niegan cualquier tipo de ascendencia. Para ellos, "no son jaqi, es decir, personas que viven bajo las normas que rigen el comportamiento humano" (Abercrombie, 1998: 324).

Vemos, por tanto que el concepto de salvaje en Latinoamérica (pero también en la Europa clásica y medieval), se define por la distancia cultural. Distancia en las costumbres y hábitos, pero también en el tiempo y en el espacio.

\section{Los apaches o brutos entre los purépechas}

De las montañas andinas del Perú y Bolivia, vayamos hasta las sierras mexicanas. Más concretamente a la Sierra Madre Occidental, localizada en el Estado de Michoacán. En su centro está asentada la conocida hoy en día como etnia purépecha pero que, en la historia, la encontramos más bien bajo el nombre de tarasca.

No puedo pasar de comentar cómo la concepción del salvaje no es, ni mucho menos, traída a América por, en este caso, los españoles. Las diferentes culturas prehispánicas que se asentaban en Mesoamérica hablaban en términos parecidos de aquellas sociedades vecinas que no formaban parte de sus Estados. Cuanto más alejadas y violentas, más salvajes eran. Existía un término claro para referirse a ellas, especialmente a aquellas provenientes del norte de Mesoamérica, el de chichimecas. El término chichimeca era algo más que un simple sinónimo de bárbaros, aunque para este trabajo nos interesa únicamente esta acepción.

López Austin y López Luján (2001: 207) afirman que debido a la escasez de información y a la imagen condicionada y peyorativa existente tras la Conquista, lo único que se puede asegurar es, que la palabra chichimeca, hace referencia a "un origen geográfico común: un vasto territorio que se extendía a ambos lados de la frontera entre Aridamérica y Mesoamérica (...)". Para los españoles, los chichimecas eran "bárbaros", de diferentes estadios culturales.

Loque sípareceevidente es que, paralas sociedades del Centro de México en la época prehispánica, los chichimecas eran esos guerreros procedentes del norte del territorio, normalmente de tierras áridas, inhóspitas y distantes.

En lo que respecta al grupo tarasco (Estado desarrollado aproximadamente entre el 1300 y el 1522 d.c.), ellos mismos aducen, en el único documento que poseemos 
para conocer su historia antes de la llegada española ( $\mathrm{La}$ Relación de Michoacán), que son de origen chichimeca: los primeros chichimecas-uacanaceos (como ellos mismos se autodenominan) se establecieron alrededor de la zona de Zacapu. Durante unos años estuvieron aislados sin entrar en contacto con los escasos grupos locales. Considerados cazadores, en principio participaron poco de la vida agrícola, hasta que su líder, Ticatame, decidió sellar una alianza con los pescadores del Lago de Pátzcuaro por medio de un matrimonio (Beltrán, 1994: 49-51). A partir de ese momento, iniciaron la conquista de gran parte de los territorios de alrededor.

A la llegada española a Michoacán, se encontraron con un Estado en pleno auge, dividido en señoríos y, cuya población, habitaba en asentamientos dispersos en las faldas de las montañas. Estas son definidas por las Crónicas de la época como "tan remotas, tan ásperas e inaccesibles montañas, de tantos y tan caudalosos ríos, de tan calientes temples, que casi son inhabitables, a lo menos por los españoles" (Crónicas de Michoacán, 1991: 84). Y a los indios que en ellas habitaban como "tan rudos, tan montaraces y brutales, que no sólo huían de las gentes, pero estábanse todavía en las quebradas y montes sin querer bajar a los llanos" (Crónicas de Michoacán, 1991: 88)..1

Los tarascos, antes de la llegada de los españoles, tenían como enemigos a los propios chichimecas del norte y a los mexicas del centro. Tras recibir a los clérigos españoles, fueron ellos quieren adquirieron la categoría de salvajes que vivían en tierras y montañas inhóspitas.

La comunidad purépecha de Sevina, que hoy se asienta en un plan o llano rodeado de cerros, fue un importante núcleo prehispánico. La propia Relación de Michoacán recoge su existencia como uno de los señoríos del Estado tarasco (de Alcalá, 2000: 467) y, las diversas fuentes, nos dicen que, siguiendo el patrón común del nuevo gobierno colonial, continuó siendo la cabecera política y religiosa de una amplia región hasta por lo menos el siglo XVIII (César Villa, 1998). La diferencia entre la época prehispánica y la posterior a la llegada de los españoles radica, principalmente, en el lugar de asentamiento: de los cerros se pasó a las llanuras.

Los actuales habitantes de la comunidad afirman que "más antes" - forma usada para referirse a ese tiempo no conocido y distante- los habitantes prehispánicos estaban localizados en cuatro lugares repartidos por los cerros colindantes, "de cuando vivían más antes ahí arriba" o "en la falda [del cerro] vivía gente, arriba de las yácatas". Todos ellos sitios de vivienda, había uno central que imaginan como el "lugar de ceremonias" ya que en él hay un "cuadro" o "atrio", que pudiera indicar la existencia de un templo. Hoy en día ese "cuadro" ocupa una amplia superficie donde se puede ver una plataforma limitada por paredes de piedras talladas. Es en este lugar donde más restos arqueológicos han hallado los sevinenses.

Aunque estos afirman que esos fueron los primeros pobladores de su territorio, no se identifican nunca claramente con ellos. Esos habitantes eran otros, aunque también purépechas. Y tienen una forma clara de referirse a ellos: los apaches. Es complicado saber de dónde viene la denominación de apaches, aunque podemos presuponer dos orígenes: uno histórico, determinado por el conocimiento desde hace centurias de las tribus del norte del país que hasta incluso el siglo XIX participaron en incursiones en el centro de México. Estas tribus eran conocidas como apaches. Por otro lado, el que los propios habitantes contemporáneos presentan, es decir, que el término viene por una danza, la danza de los apaches, traída de México D.F., a mediados del siglo pasado y que, durante varias décadas, se estuvo bailando en la comunidad.

En Sevina todo el mundo habla de esos habitantes prehispánicos de los cerros como apaches, y tienen también muy bien determinada la definición de los mismos:

\section{(...) gente bruta que no quiere ver a la gente, que no quiere conocer nada, puro en el cerro. ¿Me entiende? Así, como gente bruta, como gente que no quiere conocer aquí en el pueblo (Genaro Ramírez).}


Eran personas que iban prácticamente desnudas, tapadas únicamente con un taparrabos y un penacho en la cabeza: "lo que nosotros llamamos apaches. Una persona así semidesnuda, nada más cubierta un poco, con su penacho así..." (Jesús Valencia). Los demás complementos, como cascabeles, pinturas, lanzas y arcos y flechas, podrían o no llevarlos. El modelo está determinado también por la danza de los apaches, pues los participantes en la misma se vestían de esa forma, aunque también por la imagen grabada de un apache que está en una gran laja de piedra cercana a la comunidad. Coincide, además, con la que, por ejemplo, vemos en el llamado Lienzo de Nahuatzen, documento virreinal que pretendía justificar los derechos de los indígenas de la comunidad vecina de Nahuatzen, sobre las tierras ocupadas (Roskamp, 2004: 299).

El término "bruto" es usado siempre en la comunidad cuando se alude a los apaches, y nunca en otra ocasión. Se podría decir que apaches y brutos es sinónimo. De hecho, la danza de los apaches es también conocida como "danza bruto": "Los que vivían más antes en el cerro eran apaches, brutos (...) Andaban comiéndose entre ellos, comían víboras. El pueblo se fundó cuando esos brutos se bautizaron (...)" (Juan García). Ahora bien, existe, como presenta Juan, un elemento esencial y que alude, en primer lugar, a lo alejado del tiempo y del espacio - pues no habitaban lo habitable - y, también, a su carácter de no católicos.

Gran parte de esa imagen de brutalidad estaba determinada por profesar otra religión, la cual iba ligada a la del salvajismo caníbal, ya mostrado por Juan, pero también con la presencia de idolatrías completamente diferentes a las actuales: "Y esos adoraban, esto, piedras... y palos, adoraron. Hacían pues, monos ${ }^{12}$ de palos y esos adoraban. Ellos adoraban... y adoraban víboras" (Pedro Romero). También, parece ser, que tenían a los cuerpos celestes como dioses: al sol, las estrellas o la luna, anacuchi.

Debo comentar que no es únicamente en Sevina donde se presenta a los habitantes prehispánicos comogente bruta y salvaje. En la comunidad lacustre de Jarácuaro, los khuanhári, son esos habitantes prehispánicos, de un tamaño gigante, que fueron capaces de realizar grandes obras arquitectónicas, pero que también se caracterizan por no ser católicos y andar casi desnudos (Carrasco, 1976: 105-106). Por otro lado, en San Juan Parangaricutiro, podemos ver cómo también existen los "indios brutos", "gente sin razón que vivían como animales en cuevas y sin conocimiento de Dios" (Pla, 1983: 427). Como tal, el término apache sólo es usado, que yo sepa, en Sevina para referirse a esos habitantes prehispánicos, aunque sí es cierto que en otras comunidades como Santa Fe de La Laguna o Cherán ha existido en algún momento la denominada danza de los apaches.

Tres de los principales elementos vistos hasta el momento para asignar el salvajismo, en este caso la brutalidad, a un grupo se dan en Sevina: la desnudez, el canibalismo y el espacio.

En la Sevina contemporánea se divide el territorio en tres entornos bien definidos: el cerro, el pueblo y el plan. Este último, parece limitarse al lugar donde se sitúan los cultivos de maíz con los que sobreviven la mayoría de los sevinenses. El cerro y el pueblo son un asunto aparte, pues representan el caos y el orden respectivamente.

El sevinense considera que el pueblo es el espacio seguro donde debe situarse si no quiere sufrir daños, accidentes o sorpresas desagradables en su cotidianidad. De hecho, es el único espacio donde las mujeres y los niños tienen completa libertad para moverse. Representa claramente el orden, la civilización y la regulación por normas - propias- que en su conjunto, el costumbre, rigen la vida de sus habitantes. La formación de este espacio se sitúa tras la llegada de los españoles y la bajada de los apaches de los cerros. Es, para la comunidad, la civilización, el momento del establecimiento del catolicismo y de la normatividad comunitaria o costumbre.

Pero el entorno que nos ocupa aquí especialmente es el del cerro. El cerro está constituido por lugares 
donde suceden fenómenos que quedan lejos del control —que no del desconocimiento- del sevinense. En el cerro se aparece el diablo, muertos, se oyen campanas invisibles, se ven gigantes, se oye el viento soplar sin sentirlo, a caballos galopar sin verlos, se ven luces en la noche. Y muchos de estos sucesos se dan en las conocidas como yácatas o ruinas prehispánicas. Es el lugar donde habitaban los apaches. Es preciso apuntar que los apaches, así como sus lugares de asentamientos, aunque ligados a fenómenos sobrenaturales, no son considerados representaciones del mal, ni del diablo. Aunque producen temor y respeto, en ningún momento se asocian al diablo los fenómenos relacionados con ellos. Algo que sí sucede, por ejemplo, con los lugares adjudicados a la presencia de guerrilleros y bandoleros durante la Revolución de 1910.

Esos sucesos fuera de toda normalidad, tienen para los sevinenses, una causa evidente: aparecen en aquellos lugares donde, en un momento u otro de la historia de la comunidad, se ha enterrado a una persona. En el pueblo existe la seguridad de que "según hayas sido muerto, ahí estás (...). A veces se recoge el cuerpo, se sepulta y todo, pero la creencia que nosotros tenemos es que el espíritu ahí está, donde haya fallecido (...)". (Jesús Valencia). Toda persona que no haya sido enterrada en lugar santo, en el panteón, será un alma en pena. Por otra parte, se piensa que los apaches que no quisieron seguir las instrucciones de los frailes españoles de bajarse al plan y habitar el nuevo asentamiento, fueron ajusticiados en el mismo cerro: “(...) al negarse tuvieron que sacrificarlos allí por no entender [...]. Yo deduzco que por su negativa a bajarse acá tal vez los perjudicaron allá... los mismos españoles" (Jesús Valencia).

Por tanto, parece ser que el cerro se convierte en un lugar fuera del control comunitario por el hecho de que fue habitado por personas extrañas que, además, fueron muertas en él. Pero el camino de esta argumentación se puede hacer también de vuelta. El cerro es un lugar extraño de por sí, y todo el que lo habite corre el riesgo de convertirse en parte de esa extrañeza. En Sevina, como en la mayor parte de México (Barabas, 2003: 26), parece existir un pacto con la naturaleza, en la medida en que si es cuidada y tratada con respeto por el ser humano, ella dará alimentos y sustento a sus ocupantes. Ahora bien, este pacto existe en la medida en que a la naturaleza se le adjudica vida propia. Es decir, que posee la capacidad de regir sus terrenos y de imponer sus normas que, por otra parte, están al margen del control humano.

La humanización de elementos de la naturaleza es muy común en Sevina. Como ejemplo, tenemos el caso del conocido como paraje de El Toro. En él hay una piedra que los sevinenses afirman tiene forma de este animal, y como tal se le trata. Se habla que en época de celo del ganado, se oye un bramido desde ese lugar y que es la piedra que con ello anima al resto de los animales a copular. Pero también es donde todos los ganaderos de la región graban el sello de sus reses, de tal forma que la piedra está repleta de símbolos complejos, de letras y números. En un recorrido por este lugar, pude comprobar, incluso, cómo los comuneros le pasan un lazo por "la cabeza" y la montan al estilo como se hace en los jaripeos.

Esta autonomía en el comportamiento y en la capacidad propia de regirse que posee la naturaleza, tiene en el cerro su mayor representante. El pueblo es aquel entorno que controla el hombre, con el orden impuesto por sus normas católicas. Fuera de él, no existen estas normas y, por tanto, se convierte en el territorio donde habita "el maligno", que se suele aparece en forma de burro y otros animales aunque, principalmente, de perro, siempre fuera del pueblo. Los cuentos y leyendas lo ubican en las barrancas y las cuevas y siempre transmiten un mensaje moralizador, que castiga la transgresión de la norma por parte de un comunero. Suele estar relacionada con la bebida o con el descuido de los asuntos familiares o su responsabilidad en el trabajo.

Por tanto, el salvaje de Sevina, el "bruto" y apache, se refiere al habitante prehispánico de los cerros colindantes al actual asentamiento. Se refiere a un ser no católico, caníbal, que se comportaba casi como una 
bestia y que, aunque no representa el mal, sí habita un entorno donde se sitúa al diablo, territorio considerado alejado de las concepciones propias que se tienen sobre lo que es orden, norma y civilización.

\section{Conclusiones}

Existe una tendencia general a atribuir a toda narración sobre el mundo prehispánico el carácter de mito como veíamos para el caso de los Chullpas o los ackay en los Andes. Si, además, el relato nos habla de unos seres salvajes, alejados de la civilización y con características, en muchos casos, sobrenaturales, el mito parece consolidarse. En Sevina los apaches no forman parte de su mitología, sino tan sólo son los habitantes prehispánicos de su territorio. En primer lugar, porque así lo denominan ellos y, en ningún momento, como mito; una categoría que, en muchos casos, es construida por el investigador con sus preguntas y con la lectura y exposición escrita que hace posteriormente de él (Gutiérrez, 2001: 357). Pero, también, porque creo que es conveniente poner el acento en las "historias compiladas bajo el signo de lo fáctico" y no tanto en la "categoría de lo imaginario" (Salomón, 1994: 237).

He intentado que la imagen del salvaje-bruto que se tiene en Sevina sea lo más fiel posible a lo que aparece en la comunidad usando para ello la etnografía. Tiene la característica de ser una imagen práctica para la interpretación de la cultura propia, es decir, usada desde dentro. A diferencia de algunos de los conceptos vistos a lo largo de este trabajo, el relativo a los apaches es interior y para uso exclusivo de los propios comuneros. Con él se logra no únicamente dar un sentido y hacer propios los acontecimientos históricos, sino también darle un significado al territorio en el que habitan.

He puesto el acento en una característica que parece haber acompañado desde siempre a la idea del salvaje: la distancia. Distancia cultural, especialmente con el tiempo y con el espacio. Un persona que no pertenece a la propia cultura es más salvaje cuanto más alejada esté en el tiempo o en el espacio. Si, además, logra unir a ambas categorías, estamos hablando del bruto o salvaje por excelencia.

La distancia temporal hemos visto que no siempre existía - véase griegos y romanos o, incluso, los bugre y los huarayos en la Amazonía-, pero el alejamiento territorial ha sido una constante. Este alejamiento puede que no sea únicamente físico, sino que es suficiente con que sea cultural. En Sevina, donde incluso las últimas casas de reciente construcción ocupan las faldas de las montañas, tienen el cerro donde habitaban los apaches a menos de diez minutos caminando. Al mismo tiempo, estos cerros tampoco resultan terrenos especialmente inhóspitos. De hecho, los bosques que en ellos hay son considerados lugares que protegen tanto del clima extremo como de la desorientación. Por supuesto, que un territorio inhóspito acrecienta las condiciones de salvajismo de sus habitantes - así como el alejamiento físico-, pero quiero aquí señalar que no resulta necesario para que se cultive la idea de unos seres brutos y bárbaros.

Lo importante es que ese territorio esté fuera de lo habitado y de lo normado, al margen del orden impuesto por las reglas conocidas. Si, además, está alejado y es imponentemente accidentado, se multiplican los malos atributos tanto del terreno como de sus habitantes. Los romanos comenzaron a hablar de los bárbaros no únicamente porque los bosques donde habitaban algunos estuvieran alejados y llenos de monstruos, sino que, principalmente, porque estaban fuera del territorio regido por sus normas y su derecho.

\section{Notas}

${ }^{1}$ La palabra "civilización" parece haber sido usada por primera vez, a lo largo del siglo XVIII, no como el término bárbaro, que como dice Hurbon, fue mucho anterior, en el siglo XVI (1993: 28).

${ }^{2}$ Todos los textos que en el original están en otro idioma diferente al castellano, aparecen aquí traducidos al mis- 
mo bajo mi responsabilidad. Todos los errores que pudieran aparecer en dicha traducción son exclusividad mía.

${ }^{3}$ Los cíclopes, por ejemplo, son descritos como "un pueblo de pastores gigantes, antropófagos, que no conocían la agricultura y que vivían aislados, feroces, pero también idílicos" (Woortmann, 1997: 13).

${ }^{4}$ Estrabón establecería siglos después un par de ellas más, representadas en las costas y las islas (Caro Baroja, 159: 384).

${ }^{5}$ Aquellos que tenían acceso al saber, es decir, en su mayoría los que habitaban los monasterios. No sabemos a ciencia cierta cómo este imaginario clásico divulgado en los monasterios llegaba al común de la gente, aunque no es difícil de imaginar que se hiciera por medios como el púlpito o, como apunta Barabas, por las historias de los juglares difundidas de pueblo en pueblo (2000: 10).

${ }^{6}$ Está división temporal está determinada por el momento del nacimiento de Cristo.

${ }^{7}$ El mismo Schama nos señala como las cumbres de las altas montañas seguían siendo las moradas de dragones y serpientes gigantes, todos ellos identificados con el diablo (1995: 412-413).

${ }^{8}$ Hurbon nos muestra como debió de ser la percepción del colonizador al llegar a América: "Ante Colón, en efecto, desde el momento de desembarcar en las islas, los indios se muestran desnudos, desprovistos de leyes, de religión; no es de asombrar que ellos estén a la vez cercanos a los animales y que sean caníbales" (Hurbon, 1993: 108).

${ }^{9}$ En octubre 2003, tuve la oportunidad de asistir a una reunión de expertos en el tema en la ciudad peruana de Cuzco bajo el nombre de Seminario Binacional Perú-Brasil: "Poblaciones en aislamiento y en contacto inicial: Problemática actual y perspectivas institucionales". En dicho encuentro se dio a conocer la existencia de grupos de indígenas que todavía no han tenido contacto con la sociedad occidental o que lo han hecho sólo en contadas y reguladas ocasiones. En las jornadas se puso el acento en la protección estatal como único medio para proteger a estos grupos y regular su existencia dentro de un territorio nacional que ellos, por supuesto, desconocen por completo.
${ }^{10}$ Un caso significativo aunque marcadamente diferente, es el que presenta Howard-Malverde también para los Altos del Perú. Hablamos de los personajes prehispánicos denominados achkay, "un ser femenino pero, por ser vieja, y por comerse a los niños varones y los testículos de los hombres adultos, se podría decir que ella representa una amenaza a la reproducción humana. Lo que es más, por cocinar piedras fingiendo que éstas son papas, achkay demuestra una estado cultural semi-acabado (...)". La autora habla de los achkay como personajes que pertenecen al mito, ya que son ubicados en un tiempo sumamente alejado, "el 'tiempo de los gentiles' (...), término que denomina un periodo concebido como 'preculturizado"' (1984: 6-7).

${ }^{11}$ Extractos de la Primera Parte de la Choronica Augustiniana de Mechoacan, México, 1624, de Fray Juan González de la Fuente.

${ }^{12}$ La palabra "mono" se usa en Sevina, en este caso, para referirse a toda imagen realizada con las manos del hombre, ya sea en madera, piedra, muñecos o incluso figuras digitales. Tiene un cierto cariz peyorativo o, al menos, cómico. Las representaciones religiosas, por ejemplo, nunca son denominadas de esta forma.

\section{Bibliografía}

Abercrombie, Thomas A., 1998, Pathways of Memory and Power. Ethnography and History Among on Andean People, the University of Wisconsis Press, Wisconsin.

Barabas, Alicia M., 2000, "La construcción del indio como bárbaro: de la etnografía al indigenismo”, en Alteridades, 10 (19), pp. 9-20.

—, 2003, "Introducción. Una mirada etnográfica sobre los territorios simbólicos indígenas", en Barabas, Alicia M. (coord.), Diálogos con el territorio. Simbolizaciones sobre el espacio en las culturas indígenas de México, vol. III, INAH, México D.F., pp. 15-37.

Beltrán, Ulises, 1994, "Estado y sociedad tarascos en la época prehispánica”, en Boehm de Lameiras, B. (coord.), El Michoacán Antiguo, El Colegio de Michoacán- 
Gobierno del Estado de Michoacán, Zamora, Michoacaán, pp. 29-163.

Caro Baroja, Julio, 1959, "La ciudad y el campo, o una discusión sobre viejos lugares comunes", en Revista de Tradiciones Populares, tomo XV, pp. 381-400.

Carrasco, Pedro, 1976, El catolicismo popular de los tarascos, SEP-SETENTAS, México D.F.

César Villa, Mª Guadalupe, 1998, "Las congregaciones de pueblos de indios en tres partidos serranos y sus consecuencias en el siglo XVII", en Arquitectura y espacio social en poblaciones purépechas de la época colonial, Universidad Michoacana de San Nicolás de Hidalgo-Universidad Keio-CIESAS, Morelia, Michoacán, pp. 47-61.

Chavarría, María C., 1999, "El mundo del agua en la tradición oral ese-eja”, en Godenzzi Alegre, Juan Carlos (comp.), Tradición oral andina y amazónica. Métodos de análisis e interpretación de textos, Centro de Estudios Bartolomé de Las Casas, Cuzco (Perú), pp. 17-46.

Crónicas de Michoacán, 1991, UNAM, México D.F.

De Alcalá, Jerónimo, 2000, La Relación de Michoacán, Moisés Franco Mendoza (coord.), paleografía de Clotilde Martínez Ibáñez y Carmen Molina Ruíz, El Colegio de Michoacán-Gobierno del Estado de Michoacán, México.

Gutiérrez Estévez, Manuel, 2001, "Las diferencias contra la mitología”, en León-Portilla, Miguel (coord.), Motivos de la Antropología Americanista. Indagaciones en la diferencia, FCE, México D.F, pp. 327-365.

Howard-Malverde, Rosaleen, 1984, "Achkay: una tradición quechua del Alto Marañón”, en Chantiers Amerindia, París, (3er. trimestre).
Hurbon, Laënnec, 1993, El bárbaro imaginario, Fondo de Cultura Económica, México D.F.

Larson, Brooke, 2002, Indígenas, élites y Estado en la formación de las repúblicas andinas, Instituto de Estudios Peruanos-Universidad Católica del Perú, Lima.

López Austin, A. y López Luján, L., 2001, $\quad$ El pasado indígena, Fondo de Cultura Económica, México D.F.

Plá, Rosa, 1983, "Los mitos y las leyendas de cómo una comunidad indígena se apropió de su historia", en Sabiduría Popular, El Colegio de Michoacán, Zamora, Michoacán, pp. 423-448.

Roskamp, Hans, 2004, "El Lienzo de Nahuatzen: origen y territorio de una comunidad de la sierra tarasca, Michoacán”, en Relaciones, El Colegio de Michoacán, Zamora, Michoacán, vol. XXV, núm. 100, otoño, pp. 279-311.

Salomón, Frank, 1994, "La textualización de la memoria en la América Andina: Una perspectiva etnográfica comparada", en América Indígena, vol. LIV, núm. 4, Instituto Indigenista Interamericano, México D.F., pp. 229-261.

Schama, Simon, 1995, Landscape and Memory, Vintage Books Edition, New York.

Taussig, Michael, 1986, Shamanism, Colonialism, and the Wild Man. A Study in Terror and Healing, The University of Chicago Press, Chicago and London.

Urban, Greg, 1996, Metaphysical Community. The Interplay or the Senses and the Intellect, University of Texas Press, Austin. Woortmann, Klass, 1997, "O Selvagem e a História. Primeira parte: Os antigos e os Medievais", en Série Antropologia, núm. 227, Departamento de Antropologia, Universidade do Brasília. 